\title{
Invertir la mirada: los vacíos metropolitanos como elementos estructurantes del territorio de Estocolmo
}

\author{
Adrià Carbonell ${ }^{1}$ | Roi Salgueiro Barrio ${ }^{2}$ \\ Recibido: 30-11-2020 | en su versión final: 08-06-2021
}

Resumen

\begin{abstract}
En las últimas décadas, estudios sobre paisaje, ecología y metabolismo urbanos han enfatizado el papel primordial de las infraestructuras y los espacios no construidos en los procesos de urbanización extensiva, así como la necesidad de considerar esos sistemas como parte integral del espacio urbano contemporáneo. En este artículo, exponemos la importancia que los vacíos metropolitanos han tenido en la formación del sistema geográfico-territorial de la región metropolitana de Estocolmo, así como la relevancia del paisaje en la concepción del modelo urbano del estado del bienestar en Suecia. En el contexto sueco, los desarrollos urbanísticos suburbanos y en particular los proyectos residenciales pertenecientes al miljonprogram (el plan nacional para la construcción de 1 millón de viviendas entre 1965 y 1974) ofrecen unos casos de estudio muy significativos en el análisis del papel que los vacíos urbanos han tenido en la configuración de la ciudadregión contemporánea. El artículo analiza este proceso de urbanización para acabar sugiriendo el papel que el vacío puede ocupar en el desarrollo urbano inmediato de Estocolmo.
\end{abstract}

Palabras clave: Vacíos metropolitanos; sistemas ecológicos; territorio; paisaje

Citación Carbonell, A. y Salgueiro Barrio, R. (2021). Invertir la mirada: Los vacíos metropolitanos como elementos estructurantes del territorio de Estocolmo. ACE: Architecture, City and Environment. 16(46), 9894. DOI: http://dx.doi.org/10.5821/ace.16.46.9894

\section{Reversing the Gaze: The Role of Metropolitan Voids as Structuring Elements of Stockholm's Territory}

Abstract

\begin{abstract}
Over the last decades, studies on the urban landscape, ecology, and metabolism have emphasised the primordial role that infrastructures and unbuilt spaces play in processes of extended urbanisation, as well as the need to consider these extended systems as an integral part of contemporary urban space. In this paper, we highlight the importance that metropolitan voids had in the formation of the geographical and territorial system of Stockholm's region, as well as the role that landscape played in the urban models of Sweden's welfare state. In the Swedish context, the suburban developments of functionalist planning, and particularly the residential projects of the miljonprogram, constitute extremely valuable case studies to analyse and re-evaluate the role of unbuilt spaces as structuring elements of cities and regions. The article analyses how this urban process shaped Stockholm's region and concludes by suggesting that unbuilt spaces may take on a key role in its future development.
\end{abstract}

Keywords: Metropolitan voids; ecological systems; territory; landscape

\begin{abstract}
${ }^{1}$ Arquitecto. Profesor e investigador, KTH Royal Institute of Technology (ORCiD: 0000-0002-9764-1925), ${ }^{2}$ Doctor Arquitecto. Profesor e investigador, MIT School of Architecture and Planning (ORCiD: 0000-00018117-443X). Correo de contacto: adriacr@kth.se
\end{abstract}




\section{Introducción: contexto actual}

En las últimas décadas, estudios sobre paisaje, ecología y metabolismo urbanos han enfatizado el papel primordial de las infraestructuras y los espacios no construidos en los procesos de urbanización extensiva, así como la necesidad de considerar dichos sistemas como parte integral del espacio urbano contemporáneo. En particular, los teóricos del landscape urbanism, han propuesto ensanchar la práctica urbanística al diseño y la gestión del suelo no edificado como un proceso dinámico de reciclaje y transformación del entorno natural, en contraposición a un urbanismo caracterizado por la regulación de las formas, usos y densidades del entorno edificado (Corner, 1997, 2006; Waldheim, 2006, 2016). Más allá de la consideración de infraestructuras y sistemas de movilidad como elementos clave de la configuración territorial, una creciente preocupación ambiental ha conducido a su vez a cartografiar y cuantificar el impacto que en el entorno natural han tenido los procesos de urbanización, incluyendo en el análisis de las fábricas urbanas cuestiones como la generación de residuos, el consumo energético o la contaminación de aguas y suelos (Berger, 2006; Gandy, 2004, 2014; Barles y Lestel, 2007). Además, la creciente presión de la urbanización sobre el territorio ha despertado un giro medioambiental que ha cargado al urbanismo de una responsabilidad por demasiado tiempo olvidada, confiriendo un papel central a los sistemas ecológicos (Mostafavi y Doherty, 2010; Reed y Lister, 2014; Carbonell, 2016), llegando incluso a pensar el paisaje mismo como un componente infraestructural constitutivo del espacio urbano contemporáneo (Bélanger, 2009), e introduciendo en el análisis del espacio metropolitano metodologías, clasificaciones y tipos morfológicos del paisaje, como los descritos por Richard T.T. Forman en sus principios generales de paisajismo y ecología regional (1995).

Por otro lado, el crecimiento desigual, discontinuo y fragmentario de las grandes urbes ha dejado a su paso considerables áreas no construidas, o para ser más precisos, no edificadas. Estos espacios, unas veces delimitados como reservas de suelo o áreas protegidas, otras sencillamente sobrantes o no considerados, han ido consolidando progresivamente un sistema de vacíos metropolitanos. No nos referimos a vacíos puntuales, asimilables a la mística del descampado o del terrain vague, sino a espacios de gran envergadura y con un componente estructurante del territorio. No se trata de espacios en desuso, sino destinados a usos diversos: productivos, logísticos, recreativos o de valor ecológico y medioambiental. Por tanto, el vacío metropolitano en realidad no está en absoluto desprovisto ni vaciado de materialidad o actividad. La única carencia que lo define es la ausencia de densidad edificada que tradicionalmente se ha asociado a la ciudad. En esta misma línea, Manuel de Solá-Morales definió el vacío como un lleno, refiriéndose a él como un "territorio magmático y heterogéneo, a la vez que visual y táctil” (2009). En esta metrópolis fragmentaria y discontinua, el espacio urbano no se mediría desde su correspondencia con el espacio edificado, ni tampoco con el pavimentado, sino desde la consideración de todo espacio alterado por la acción humana - por tanto, construido- incluido en un modelo dialéctico, expansivo y territorial. Este cambio de perspectiva implica la necesidad de atender con decisión los espacios que hemos nombrado vacíos metropolitanos, transformando lo que a menudo consideramos como fondo en figura. Centrar la atención en el análisis espacial de los vacíos como elementos estructurantes y generadores permitiría desarrollar una morfología urbana que tratase como objeto de estudio y base de proyecto lo que habitualmente queda descartado como secundario o tangencial.

La paisajista danesa Ellen Braae ha descrito cómo la creciente urbanización de los territorios metropolitanos ha supuesto la aparición de proyectos y cartografías que combinan el planeamiento y el paisajismo, y que articulan una nueva escala regional (Braae, 2015). La progresiva metropolización del territorio ha originado la puesta en valor de una herencia paisajística integrada en la metrópolis moderna, y asimismo la formulación de un nuevo tipo regulatorio, el green heritage, asociado a la consideración del paisaje como elemento patrimonial depositario de un valor social y cultural a preservar (Braae y Bøggild, 2015). Paisaje aquí se refiere tanto al espacio geográfico natural

ACE, 16 (4.6) CC BY-ND 3.0 ES | UPC Barcelona, España | Invertir la mirada: los vacíos metropolitanos como elementos estructurantes del territorio de Estocolmo. DOI: http://dx.doi.org/10.5821/ace.16.46.9894 
preexistente, como a aquellas intervenciones culturales sobre ese espacio que lo han mantenido como vacío, inafectado por la edificación. En este artículo nos centraremos en la importancia que los vacíos metropolitanos han tenido en la formación del sistema geográfico-territorial de la región de Estocolmo, siguiendo un marco conceptual que extiende la propuesta de Braae. Historiográficamente, evaluaremos la relevancia del paisaje en la concepción moderna del modelo urbano del estado del bienestar en Suecia, para evaluar los retos que este modelo afronta hoy, y concluir con una reflexión sobre como el caso de Estocolmo nos ayuda a entender otros territorios metropolitanos.

\section{Modernidad, vacío y paisaje}

La noción de vacío estuvo bien arraigada tanto en la estética como en las ideologías espaciales de la modernidad (Salgueiro Barrio, 2016). En el caso del urbanismo moderno jugó un papel esencial para sanear y airear la sobre-densificación y salubridad de las ciudades industriales, pero también para construir un nuevo paradigma espacial. Los barrios residenciales suburbanos fueron diseñados como configuraciones abiertas en torno al vacío; ese fue su gran valor en el momento de su concepción, pero también la principal fuente de crítica posterior por su acusada falta de "urbanidad", por el exceso de espacio abierto, su baja intensidad de usos y su aspecto desolado. Críticas que con el paso del tiempo han derivado en algunos casos en una estigmatización social, pero que en otros se han convertido en una cualidad, precisamente por su componente paisajística y por las posibilidades de uso y apropiación de sus vacíos debido a su generosa proporción de espacios verdes.

En el contexto sueco, los desarrollos urbanísticos suburbanos ofrecen unos casos de estudio muy significativos para el análisis del papel que los vacíos urbanos han tenido en la configuración de la ciudad-región contemporánea. Especialmente, los proyectos residenciales del miljonprogram-el plan nacional para la construcción de 1 millón de viviendas entre 1965 y 1974-propiciaron un desarrollo expansivo y confirieron a la ciudad una escala territorial con base en una sólida red de transporte público y privado, entrelazada a una red de vacíos urbanos. Los complejos residenciales del miljonprogram se deben enmarcar en un proceso de construcción metropolitana que empezó a principios de los años 30, derivado de los principios del urbanismo funcionalista de la ortodoxia moderna alemana.

El modelo de los primeros desarrollos residenciales en la periferia de la ciudad central, se apoyó en el concepto alemán de Trabantenstadt, un sistema urbano descentralizado donde la ciudad se divide generando un crecimiento urbano de núcleos separados por espacios verdes y dotados de un buen sistema de transporte (Heynen, 1999). De forma similar al proyecto Das Neue Frankfurt de Ernst May, el acceso a una vivienda moderna liberaría a la población de condiciones de infravivienda y saturación, permitiendo así el acceso de la población urbana a unos estándares mínimos de confort y contacto directo con la naturaleza, representando así el nuevo espíritu de la modernidad y los valores del sujeto moderno. Ciertamente, L'Esprit Nouveau de Le Corbusier influyó de forma decisiva en Uno Åhrén, representante por Suecia en las primeras ediciones de los CIAM, y uno de los principales teóricos y propagandistas en cuestiones de construcción urbana en Estocolmo y Gotemburgo. Fue Åhrén quien más tempranamente y de manera más incisiva introdujo los nuevos principios funcionalistas en el debate sueco (Figura 1). A su vez, defendió la idea de que el urbanismo no era una práctica artística y subjetiva, sino una ciencia exacta, un artefacto organizado para satisfacer las necesidades de la vida de la mejor forma posible, marcando así un claro distanciamiento respecto de la generación anterior de urbanistas, principalmente Per O. Hallman, seguidores de las teorías de Camillo Sitte. Posteriormente, después de la realineación política y cultural europea posterior a la segunda Guerra mundial, las fuentes de influencia del urbanismo sueco gravitaron hacia la cultura anglo-sajona, tomando como modelo e inspiración las New Towns británicas.

ACE, 16 (4.6) CC BY-ND 3.0 ES | UPC Barcelona, España | Invertir la mirada: los vacíos metropolitanos como elementos estructurantes del territorio de Estocolmo. DOI: http://dx.doi.org/10.5821/ace.16.46.9894 
Figura 1. Diagrama comparativo entre dos disposiciones de vivienda
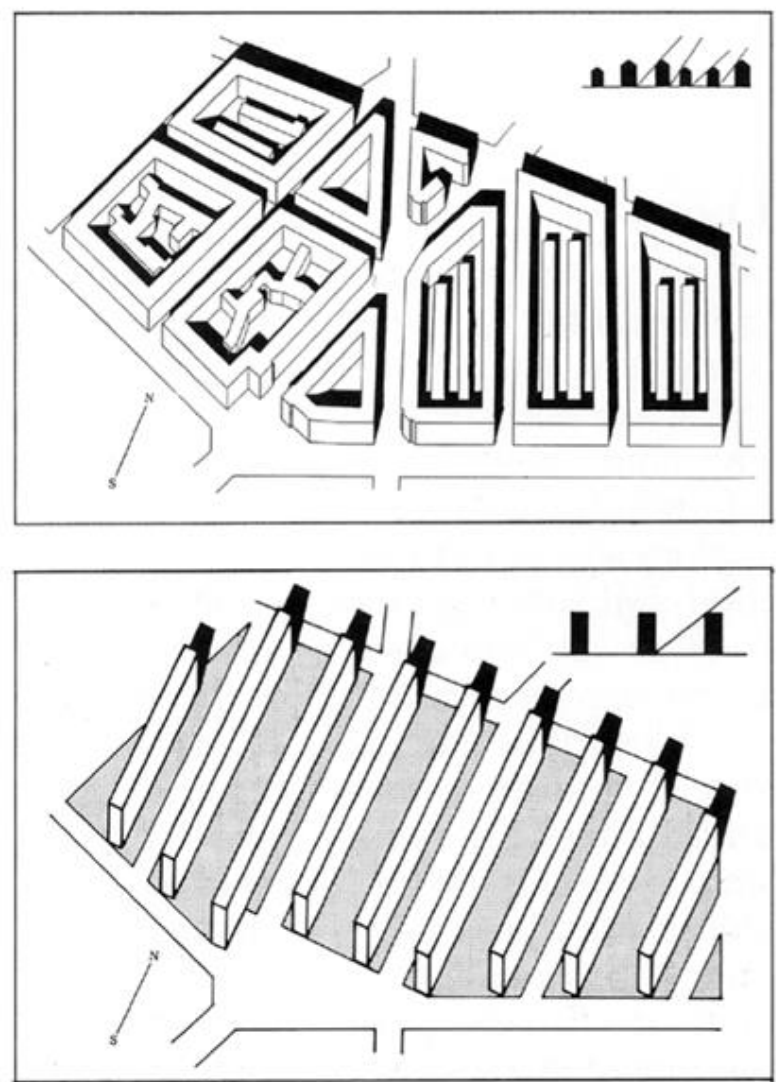

Nota: Esquema de edificación en bloque cerrado según alineación a vial y nueva disposición moderna de vivienda colectiva liberando espacio y organizando la edificación en franjas de "vacío." Fuente: Åhrén et al., 1931.

La gran operación de modernización de la economía y la sociedad en Suecia es inseparable del proyecto de construcción nacional socialdemócrata que estableció las bases de un estado del bienestar que perduró hasta finales del s. XX. Con el objetivo primordial de proveer vivienda accesible para la creciente clase media sueca -que sería el estadio ideal de la socialdemocracia: la incorporación de la población rural a la vida urbana conformando así una única clase-, el proyecto moderno funcionalista se apoyó en un proceso de emancipación económico y social, basado en la creencia que progreso y bienes de consumo conllevarían el acceso a un nuevo momento civilizatorio. Este proceso de transformación social había comenzado de forma explícita con la organización de la Exposición Internacional de Estocolmo en 1930, seguida por el manifiesto Acceptera (Acepta) de 1931, escrito por un grupo de reputados arquitectos, urbanistas e intelectuales de lo que podría llamarse la vanguardia sueca, entre ellos Uno Åhrén, Sven Markelius o Erik Gunnar Asplund. En el manifiesto se llamaba a aceptar las nuevas condiciones y tecnologías que la modernidad ofrecía, y se defendía la industrialización de la ciudad y del campo, en otras palabras, la extensión de los procesos de urbanización más allá de la ciudad, promoviendo el desarrollo industrial y la optimización del trabajo en todos los ámbitos de la vida y la economía (Mattsson y Wallenstein, 2010). La nueva ciudad, expresión de una sociedad avanzada y moderna, establecía una nueva conexión con la naturaleza, y emergía como un nuevo paisaje capaz de fundir campo y ciudad. El despliegue territorial de estas ideas en la práctica fue posible gracias a grandes inversiones y políticas de adquisición de suelo público, reforzadas por el compromiso y la colaboración entre varios niveles de la administración, desde el municipal al estatal. 
Sven Markelius, figura clave en el proceso de crecimiento metropolitano y director de la oficina municipal de urbanismo entre 1944 y 1954, presentó en 1946 el programa titulado Det framtida Stockholm (El Estocolmo del futuro), donde se marcaban las líneas estratégicas del nuevo urbanismo, fuertemente influenciado por el modelo del Neighbourhood Unit (Legeby, 2013)1. La propuesta de Markelius promovía la expansión de la ciudad mediante un sistema de núcleos multifuncionales colgando de una red de infraestructuras de transporte vial y ferroviario, que garantizaban la buena conectividad con la ciudad central, pero que al mismo tiempo procuraba un sentido de comunidad y una proximidad con el paisaje y la naturaleza (Figuras 2 y 3). En tanto que, concebidos como núcleos autónomos, las unidades-distrito se planifican en torno al vacío como un sistema de distancias optimizadas por las relaciones entre sus zonas funcionales y los tiempos de desplazamiento. De este modo, separadas entre sí por espacios no edificados y enlazadas por una red de transporte público, la metrópolis se fue extendiendo en el territorio de forma discontinua, siendo las distancias entre barrios - los vacíos - tan importantes como su cohesión interna y su conectividad con el centro.

Figuras 2 y 3. Diagramas de unidades de distrito elaborados por Sven Markelius incluidos en el plan general de Estocolmo de 1952
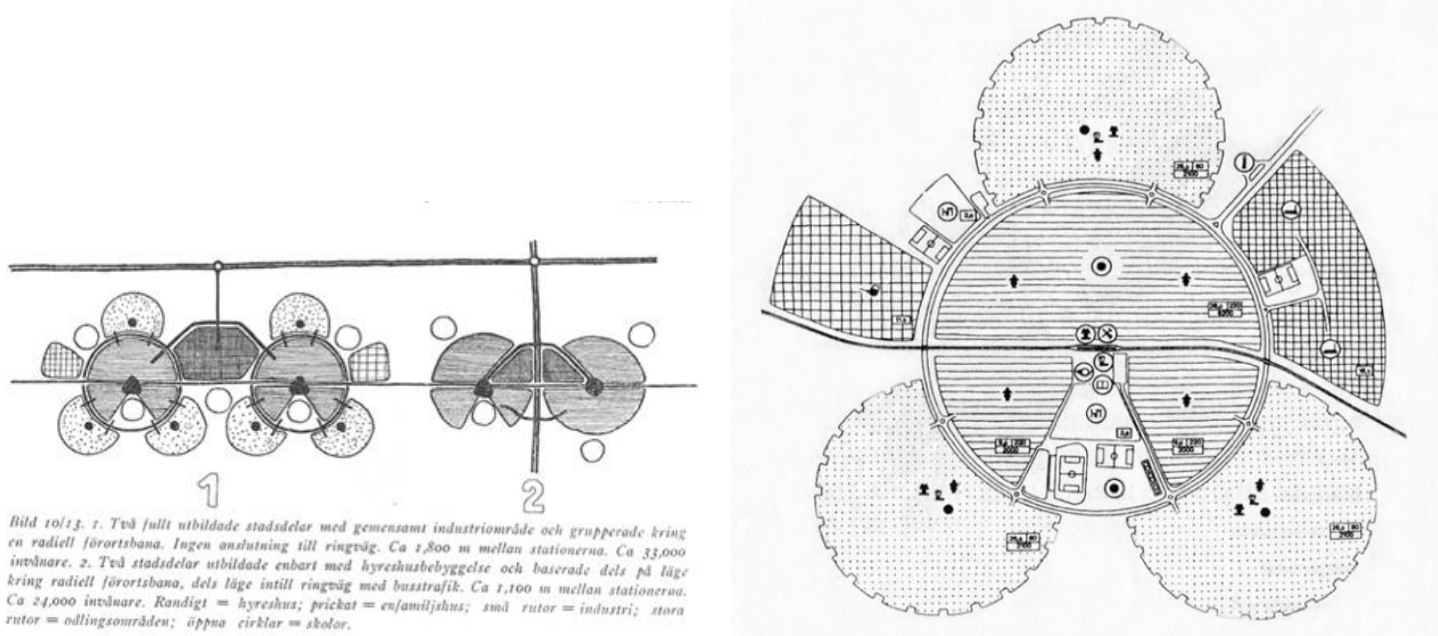

Nota: La propuesta de crecimiento se articula en torno a nodos urbanos multifuncionales conectados a una red de transporte que garantiza la buena conectividad con la ciudad central, pero que a su vez permite organizar el crecimiento en relativamente pequeñas comunidades-distrito en contacto con el entorno natural, adecuadamente separadas por vacíos no edificados. Fuente: Stockholms Stadsplanekontor, 1952.

En esta primera fase de metropolitanización de la ciudad que siguió al plan Det framtida Stockholm de 1952 se construyeron numerosos barrios satélite. Entre ellos, el más internacionalmente reconocido es sin duda Vällingby, una versión más elaborada de los esquemas presentados en el plan general, diseñada también por el propio Markelius e inaugurada en 1954. El proyecto para Vällingby es la expresión más vívida y exitosa de lo que se llamaron ABC-stad (ciudades ABC). El acrónimo, refiriendo las tres funciones fundamentales de Arbete (trabajo), de Bostad (vivienda), y de Centrum (centro comercial y cultural), apuntaba a la voluntad de construir suburbios autónomos, alejados de la hiper-densidad de la ciudad central (se proponía reducir la densidad en un 40\%), y con todas las actividades necesarias para la vida urbana accesibles sin necesidad de largos desplazamientos. Las $A B C$-stad se organizaban en base a un criterio de integración basado en la harmonía entre sus funciones, en la diversidad de tipos de vivienda y la riqueza del paisaje natural. Al igual que los posteriores proyectos residenciales incluidos en el miljonprogran, que seguirán un modelo próximo a

\footnotetext{
${ }^{1}$ Los distintos niveles de planeamiento urbanístico en Suecia establecen directrices y recomendaciones en la mayoría de casos, incluyendo los planes regionales (regional utveckling / regionalplanering) y los planes generales (översiktplan). El documento de planeamiento que se aprueba como documento legal estableciendo así criterios de cumplimiento obligatorio es el plan de detalle (detaljplan).
}

ACE, 16 (4.6) CC BY-ND 3.0 ES | UPC Barcelona, España | Invertir la mirada: los vacíos metropolitanos como elementos estructurantes del territorio de Estocolmo. DOI: http://dx.doi.org/10.5821/ace.16.46.9894 


\section{ACE Architecture, City and Environment}

Los polígonos de vivienda, las $A B C$-stad fueron concebidas justamente en el marco de una estrategia de descentralización y de imbricación ciudad-paisaje. Si su principal fundamento fue la provisión de viviendas de calidad a precio asequible para toda la población, su morfología suponía un despliegue territorial y el consiguiente entramado paisajístico-infraestructural.

Como consecuencia de la estrecha interconexión entre redes de transporte y barrios periféricos, el proceso de urbanización de la escala metropolitana de Estocolmo se configuró según desarrollos lineales de forma similar al Finger Plan de 1947 para Copenhague. Aunque su estrategia regional no estuviera diseñada de antemano, en el proceso de desarrollo suburbano se optó por un sistema de corredores o cuñas verdes (conocidos en sueco como gröna kilar) que penetran y se entrelazan con el sistema de crecimiento urbano. El modelo de corredores verdes se opone al modelo de cinturón verde (green belt), la opción tomada por otras ciudades para proteger reservas naturales en la ciudad, siendo mucho más flexible e ilimitado, en tanto que no define un límite de crecimiento de la ciudad central (Figura 4).

Figura 4. Mapa del plan general de Estocolmo de 1952

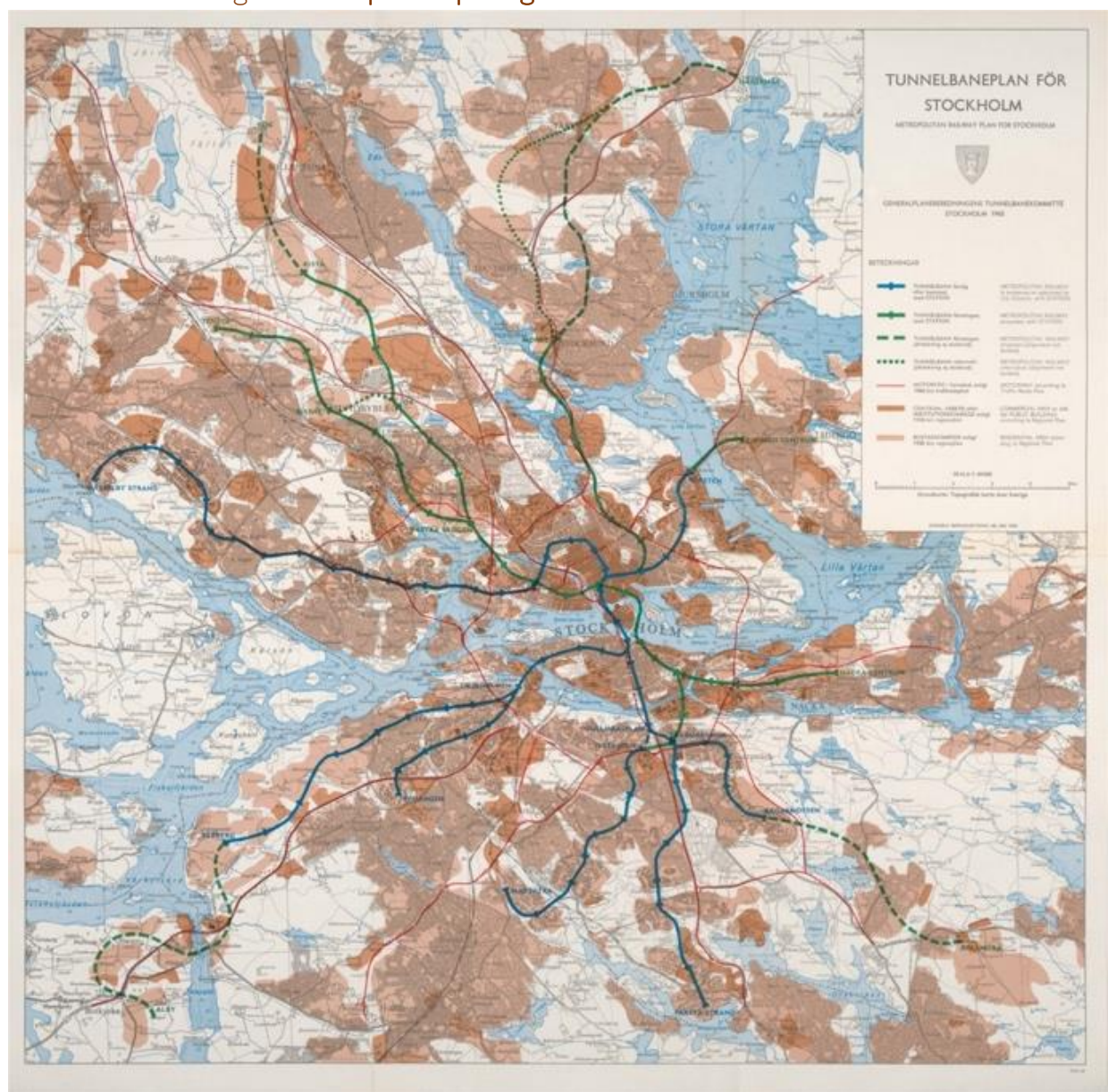

Nota: Muestra la relación entre sistemas de movilidad y crecimiento suburbano. En verde y azul las líneas del Tunnelbana, el metropolitano de Estocolmo, y en rojo la red de autovías para el transporte rodado privado. Fuente: Stockholms Stadsplanekontor, 1952.

A pesar de haber logrado una remarcable mejora de los estándares de habitabilidad gracias a la rápida renovación del parque de vivienda, y una gran generosidad en la preservación de espacios naturales, uno de los principales problemas de las ciudades satélite y de los distritos suburbanos es el de la

ACE, 16 (4.6) CC BY-ND 3.0 ES | UPC Barcelona, España | Invertir la mirada: los vacíos metropolitanos como elementos estructurantes del territorio de Estocolmo. DOI: http://dx.doi.org/10.5821/ace.16.46.9894 
segregación espacial. Se trata de un problema compartido por muchos de los barrios construidos dentro del miljonprogram, derivados de un proceso e ideología de planeamiento urbano funcionalista consistente en la segregación de funciones y la definición de áreas de desarrollo. La falta de continuidad de los tejidos urbanos de dichos distritos, conectados a través de infraestructuras viales y espacios verdes, ha facilitado un cierto aislamiento social y una cierta introversión de sus comunidades (Legeby, 2013). La claridad y compacidad con la que el modelo de las ABC-Stad resolvía la organización de sus núcleos respondía a las necesidades propias de cada unidad, dotándola de una cierta autonomía funcional. Sin embargo, atendió escasamente a las relaciones entre ellas. El caso de Estocolmo es paradigmático y singular en su condición dispersa y fragmentaria, motivada por la propia configuración de su orografía, un archipiélago compuesto por más de 20.000 islas e islotes, a la vez que por sus modelos de planeamiento. La estructura de archipiélago de Estocolmo, pues, no es meramente conceptual sino literal en su sentido geométrico y material, reproduciendo también la configuración en islas como patrón urbanizador (Figura 5). Si la ciudad tradicional se ha basado en la continuidad de sus tramas y tejidos, la región metropolitana de Estocolmo está construida sobre su discontinuidad, constituyéndose en un territorio diseminado y heterogéneo.

Figura 5. Expansión de Estocolmo en 1955 después de las primeras décadas de

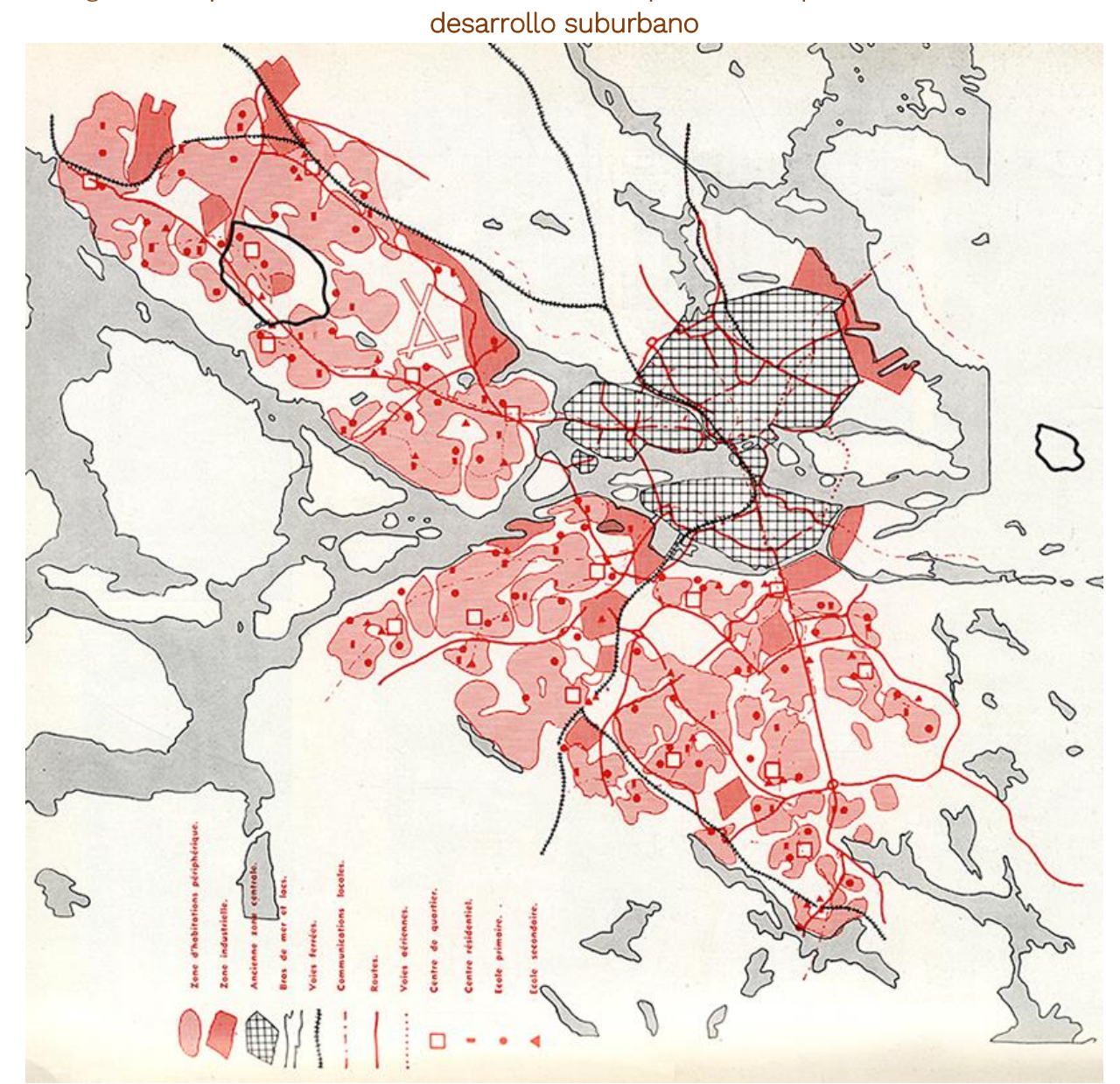

Nota: Se observa claramente la estructura de unidades diferenciadas sobre un espacio dibujado como vacío. Fuente: Architecture D’aujourd'Hui 63, 1955. 


\section{Crecimiento metropolitano y corredores verdes}

En 1965 el parlamento sueco aprobó un plan de gran ambición que tenía por objetivo resolver de forma definitiva la perene escasez de vivienda en Suecia a la vez que renovar un parque antiguo y con malas condiciones de habitabilidad. De esta manera se puso en marcha el ya mencionado miljonprogram, que afrontaba el reto de construir un millón de unidades de vivienda en todo el territorio nacional dentro de un período de diez años. Aunque surgió como iniciativa del gobierno social-demócrata, la implementación del programa a escala nacional requirió de la cooperación del sector público-privado, de ayuntamientos y agentes de la construcción, que de manera coordinada promovieron una radical transformación del parque nacional de vivienda a la vez que impulsaron la economía y desarrollaron sistemas avanzados de estandarización y prefabricación.

En el territorio metropolitano de Estocolmo, el miljoprogram supuso la construcción de unas 180,000 unidades de vivienda al ritmo de un distrito nuevo al año (Figura 6). Uno de los casos más relevantes y estratégicos, también más discutido y problematizado, fueron los cinco distritos levantados en el área de Järvafältet. Allí se ubican algunos de los proyectos tardíos del miljonprogram, entre ellos el barrio de Tensta, el de mayor tamaño de todo el programa y también el más criticado desde prácticamente el momento de su construcción (Bengtzon et al., 1970). Con el paso de los años, Tensta se convirtió en uno de los distritos más estigmatizados debido al alto porcentaje de población de origen migrante y a su baja renta económica (Höjer et al., 1997). Järvafältet es el nombre con que popularmente se designa a las áreas de Järva-Spånga-Järfälla-fältet, que corresponden a un total de unas 5,300 hectáreas de suelo público, de las cuales unas 4,000 hectáreas estuvieron calificadas cómo reserva militar desde 1905, quedando el resto de los terrenos destinados a campos de cultivo en régimen de renta-alquiler hasta la llegada de los desarrollos residenciales.

Figura 6. Desarrollo de la edificación en la región de Estocolmo durante el s. XX
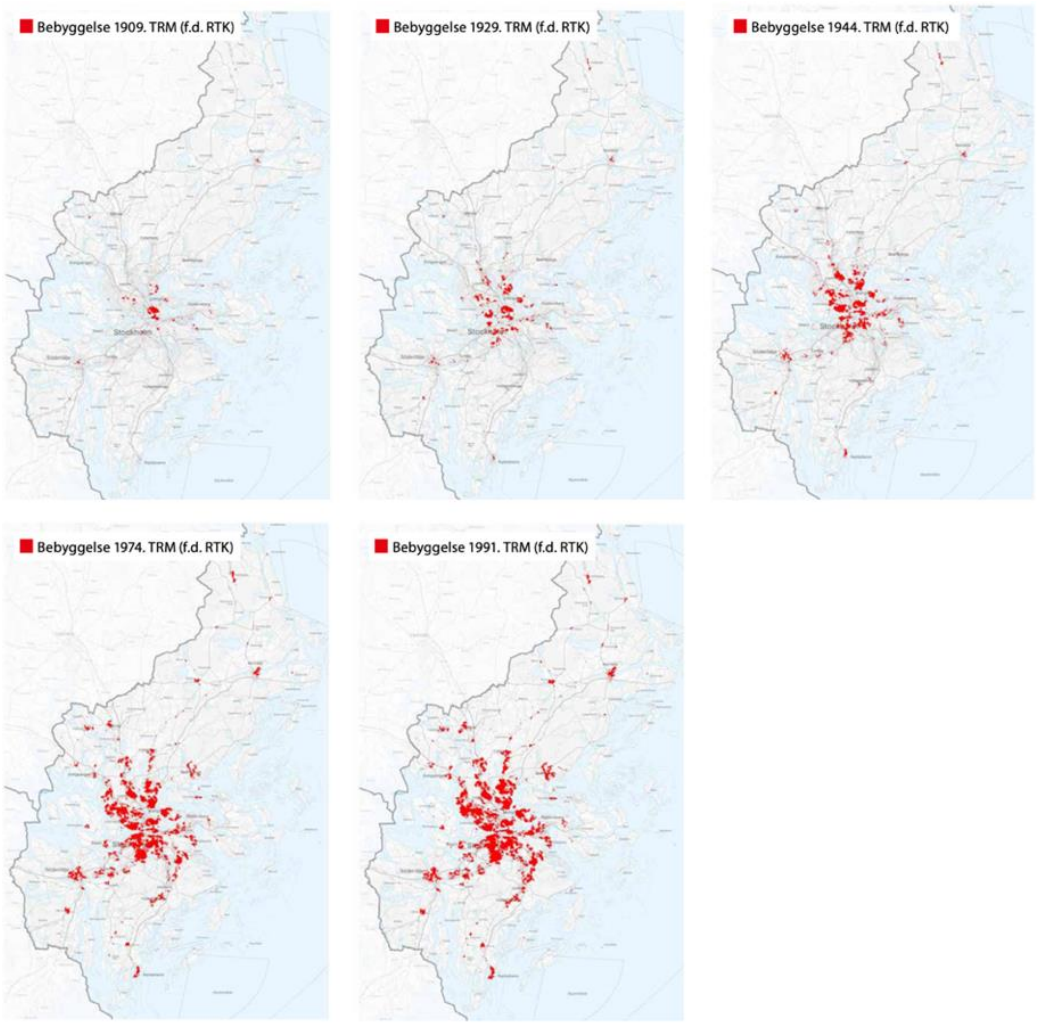

Fuente: RUFS, 2018

ACE, 16 (4.6) CC BY-ND 3.0 ES | UPC Barcelona, España | Invertir la mirada: los vacíos metropolitanos como elementos estructurantes del territorio de Estocolmo. DOI: http://dx.doi.org/10.5821/ace.16.46.9894 


\section{ACE Architecture, City and Environment}

E-ISSN 1886-4805

Los terrenos de Barkarby, situados en la parte norte del área, fueron campos de cultivo hasta los años 30, cuando se destinaron a aviación y actividades militares, implicando así un acondicionamiento de la topografía a sus nuevos usos a través de una nivelación del terreno. Las operaciones militares dejaron de usar la zona a finales del s. XX, pero el vació urbano permaneció como reserva militar en caso de ser requerido en el futuro, siendo objeto hoy día de un plan de densificación urbana.

Järvafältet se planificó durante las décadas de 1960 y 1970 como la suma de varios proyectos yuxtapuestos, netamente diferenciados y sin continuidad en sus tramas viarias. Esa discontinuidad ilustra claramente el papel determinante de los vacíos en la configuración del territorio a distintas escalas, desde el barrio-distrito y sus composiciones abiertas, a la penetración de los corredores verdes en las zonas residenciales y su dilatación en sistema regional (Figura 7). El patrón segregativo a nivel de distrito y la estructura en islas a escala territorial propicia, por otro lado, la consolidación de zonas libres de edificación. Järvakilen es uno de los siete corredores-cuña a lo largo de los cuales se ha organizado un crecimiento urbano lineal y radial del territorio metropolitano de Estocolmo. Como ha sido ya remarcado con anterioridad, las propuestas urbanas provenientes de Inglaterra tuvieron gran influencia en el desarrollo del urbanismo moderno en Suecia. La influencia más palpable es la doble estrategia de un cinturón verde circular y unos corredores transversales interconectando una trama de vacíos del plan de Abercrombie para el Greater London (el plan metropolitano para el Gran Londres). Esas ideas fueron recogidas por Göran Sidenbladh, colaborador de Markelius en sus años como jefe de la oficina de planeamiento, y posterior responsable de definir las directrices del plan para Tensta y Rinkeby a lo largo del Järvakilen (corredor de Järva).

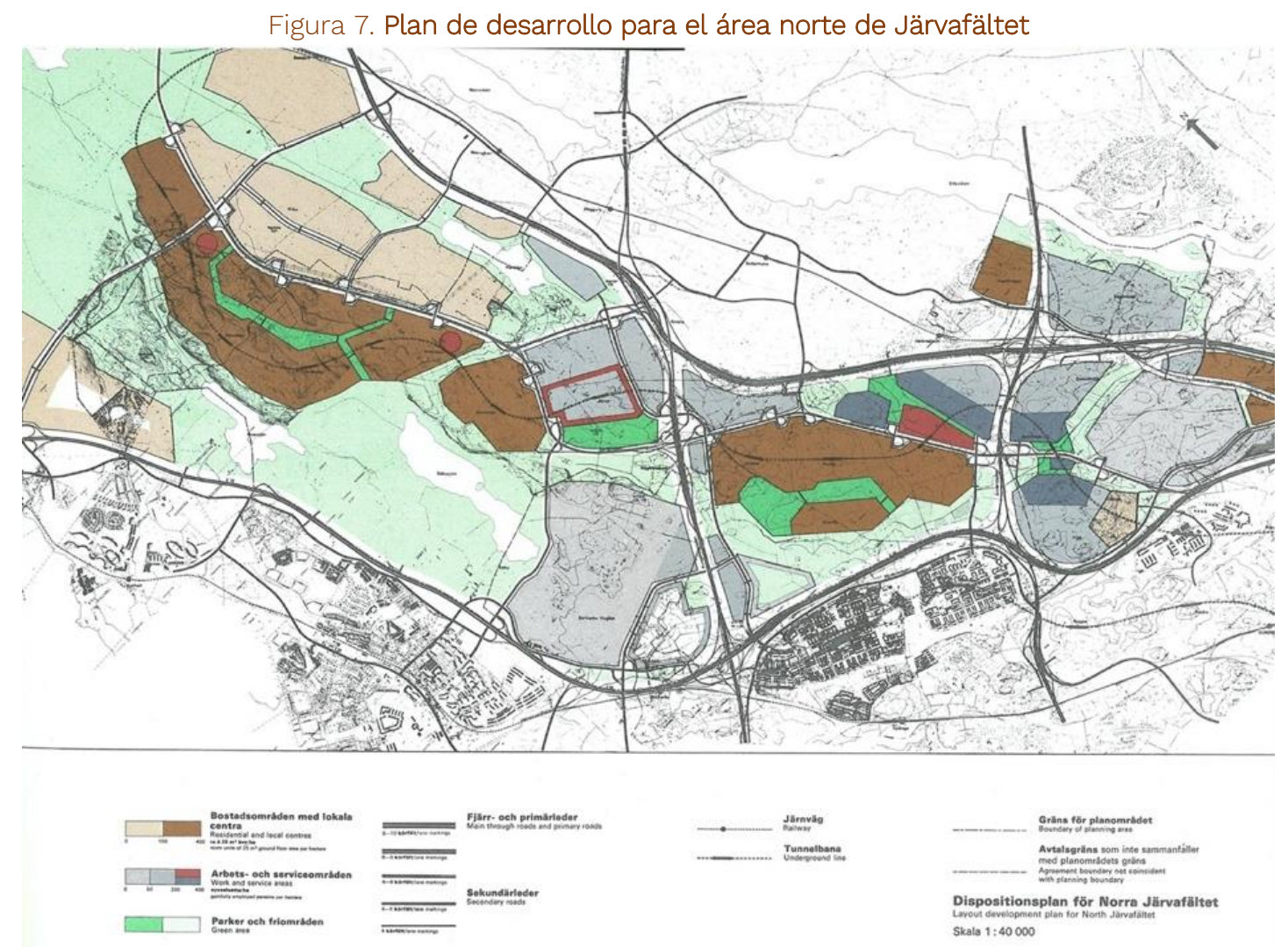

Nota: Elaborado según directrices de Göran Sidenbladh, Igor Dergalin, Thomas Atmer y Josef Stäck entre otros, se observa la relación entre redes de transporte y zonas funcionales a lo largo del corredor verde de Järva. Fuente: Arkitektur 1, 1969.

ACE, 16 (4.6) CC BY-ND 3.0 ES | UPC Barcelona, España | Invertir la mirada: los vacíos metropolitanos como elementos estructurantes del territorio de Estocolmo. DOI: http://dx.doi.org/10.5821/ace.16.46.9894 
En las nuevas directrices que Sidenbladh redactó para el planeamiento de la zona de Järva se introdujeron nuevas distancias entre edificios, cruces viarios, calles de acceso a viviendas, así como nuevas consideraciones sobre la densidad y el uso de los espacios abiertos, dejando atrás los ideales de la ciudad jardín y el paradigma moderno de los bloques de vivienda colectiva integrados en el paisaje-parque (Sidenbladh, 1969). Estos nuevos desarrollos destinaron la estructura del vacío a estructurar una escala mayor, la de los ejes-corredor verdes, persiguiendo en el interior de los barrios una mayor densidad y racionalización del espacio. En definitiva, los distritos de la zona sur de Järva, principalmente Tensta, Hjulsta y Rinkeby, eran parte determinante del conocido como plan BombaJärva, que aspiraba a resolver el perpetuo déficit de vivienda en Estocolmo construyendo un nuevo distrito urbano para 35.000 personas en tan solo cinco años. A su vez, los vacíos entre núcleos residenciales y redes de transporte fueron integrados como sistema paisajístico y de recreo desde los primeros esquemas de ordenación, incorporando el inventario de elementos paisajísticos de la zona que anteriormente había llevado a cabo Ulla Bodorff, pionera de la arquitectura del paisaje en Suecia.

Con esta última expansión, a finales de los años 70 el crecimiento metropolitano de la ciudad de Estocolmo alcanzó los límites de su municipio. Como consecuencia de ello el departamento de planeamiento de la ciudad empezó a desarrollar estrategias de densificación en lugar de crecimiento o de expansión, lo que constituiría la base de un nuevo plan general de la ciudad finalmente aprobado en 1999, con un título suficientemente elocuente: Construyendo la ciudad hacia adentro (Building the City Inwards). Esto supuso un giro fundamental en la estrategia urbanística e implicó la sustitución de los modelos vigentes hasta la fecha basados en una planificación del crecimiento y el desarrollo urbanos, con especial intensidad entre las décadas 1930-70, como hemos visto anteriormente. En el marco del nuevo plan general (översiktplan), y vista la dificultad de elaborar un proyecto comprensivo de densificación, la municipalidad de Estocolmo realizó un nuevo trabajo cartográfico centrado en la definición y categorización de los espacios abiertos no edificados con un valor "ecológico, social y cultural” (Sthåle, 2006). El documento recibió el nombre de "Carta verde de Estocolmo", y se dividió en dos mapas: el biotope map y el sociotope map, uno centrado en elementos ecológicos y otro en aspecto socio-culturales. Hasta la fecha, todo espacio no edificado era considerado "espacio verde", sin grandes distinciones entre espacios pavimentados, parques, plazas, canchas deportivas, más allá de un genérico parque/bosque, de modo que los dos mapas de la Carta verde constituyeron una remarcable innovación en cuanto a la forma de cartografiar la ciudad. Sin embargo, dichas cartografías permanecieron a un nivel de definición relativamente genérico, y no entraron a valorar la especificidad de sus aspectos cualitativos, espaciales o funcionales (Figura 8).

El documento que despertó más interés fue el citado sociotope map, en tanto que permitía elaborar una cierta categorización de los espacios abiertos en relación a su valor de uso conferido por la ciudadanía, estableciendo así un mecanismo de participación social en su cualificación, al tiempo que ofrecía una nueva metodología cartográfica y expandía la consideración de espacio público. Según la definición dada por Alexander Sthåle, uno de los creadores del mapa y del concepto, el término sociotop emerge en clara relación al de biotop, pero focalizado en los usos sociales del espacio: "la percepción común sobre el valor de uso de un lugar definido por una cultura o grupo específico". Aunque la contraposición que hace Sthåle $(2006,64)$ en el sociotop map entre el espacio vivido de los ciudadanos (life world) y el conceptualizado de urbanistas y arquitectos (system world) nos parece en cierta medida reductivo y falto de congruencia, el trabajo tiene el valor de incorporar a los mecanismos de planeamiento una serie de nuevas figuras y clasificaciones que conciernen únicamente al espacio no edificado.

De forma más reciente, y en respuesta una vez más al gran incremento poblacional de las últimas décadas, Boverket, la autoridad nacional en políticas de planeamiento, remarcó en dos documentos de 2007 la importancia de considerar y preservar "zonas verdes" en el crecimiento regional (2007a,

ACE, 16 (4.6) CC BY-ND 3.0 ES | UPC Barcelona, España | Invertir la mirada: los vacíos metropolitanos como elementos estructurantes del territorio de Estocolmo. DOI: http://dx.doi.org/10.5821/ace.16.46.9894 


\section{ACE Architecture, City and Environment}

b). En un nivel de administración superior al municipal, la autoridad competente en planeamiento regional (RTK) destacó a su vez la importancia de la preservación del sistema de espacios verdes y sus distintos biotopos desde la doble perspectiva de espacio de ocio y de valor medioambiental, en un informe de 2008, donde ofrece dos escenarios para el futuro crecimiento regional, uno de descentralización (fördelad) y otro de recentralización (tät) (RTK, 2008). Esta presión urbanizadora, junto a la importancia que los sistemas verdes tienen en la ciudad metropolitana, están forzando a definir con mayor claridad y precisión las cualidades y morfologías de los llamados vacíos (Figura 9).

Figura 8. Estructura verde de Estocolmo aparecida en el Plan general de 1999

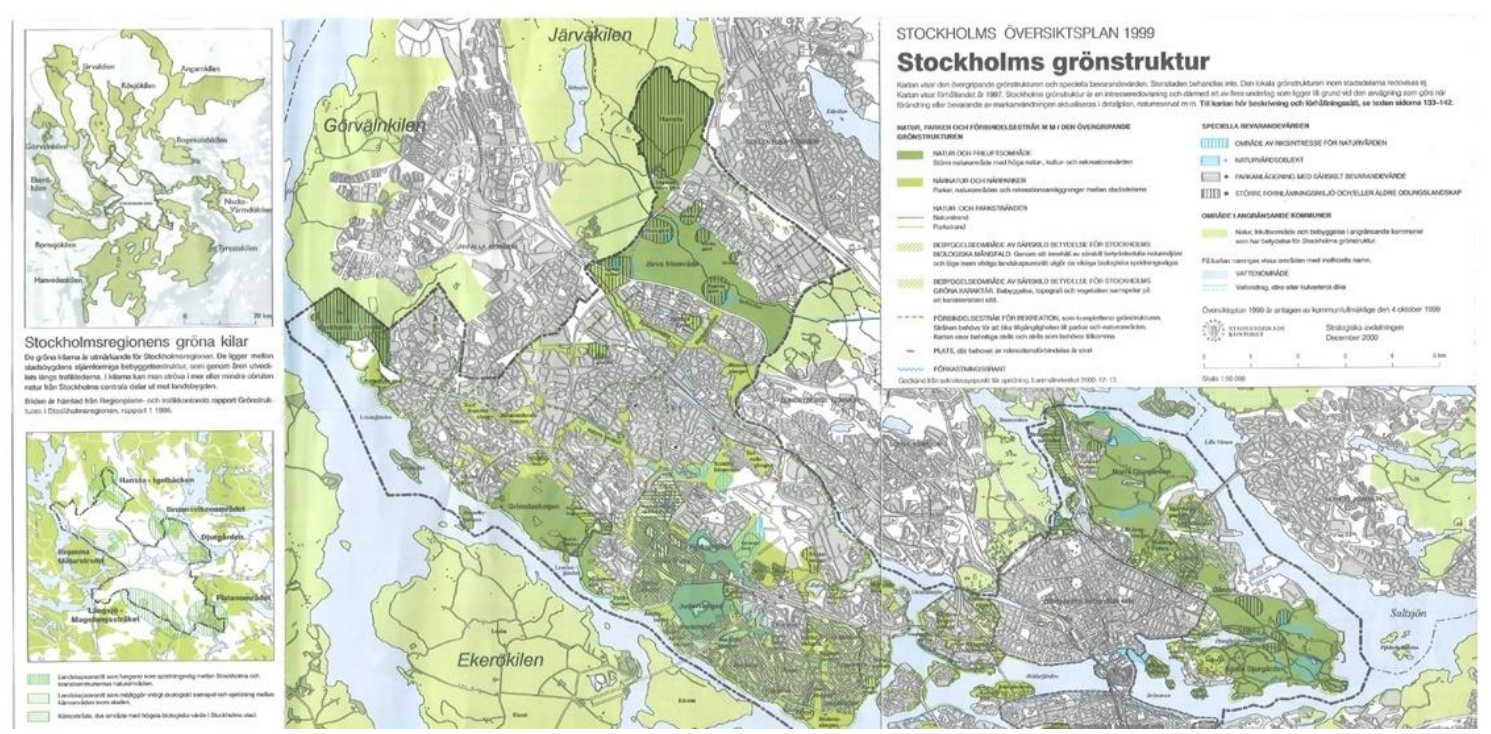

Nota: En la parte izquierda se pueden observar dos mapas que definen los corredores verdes (gröna killar) como sistema regional en relación con los límites administrativos del municipio de Estocolmo. Fuente: Stockholms Översiktplan, 1999.

Figura 9. Estudio de la distribución espacial de usos del suelo en el área definida por el Stockholm Urban Assesment de 2006

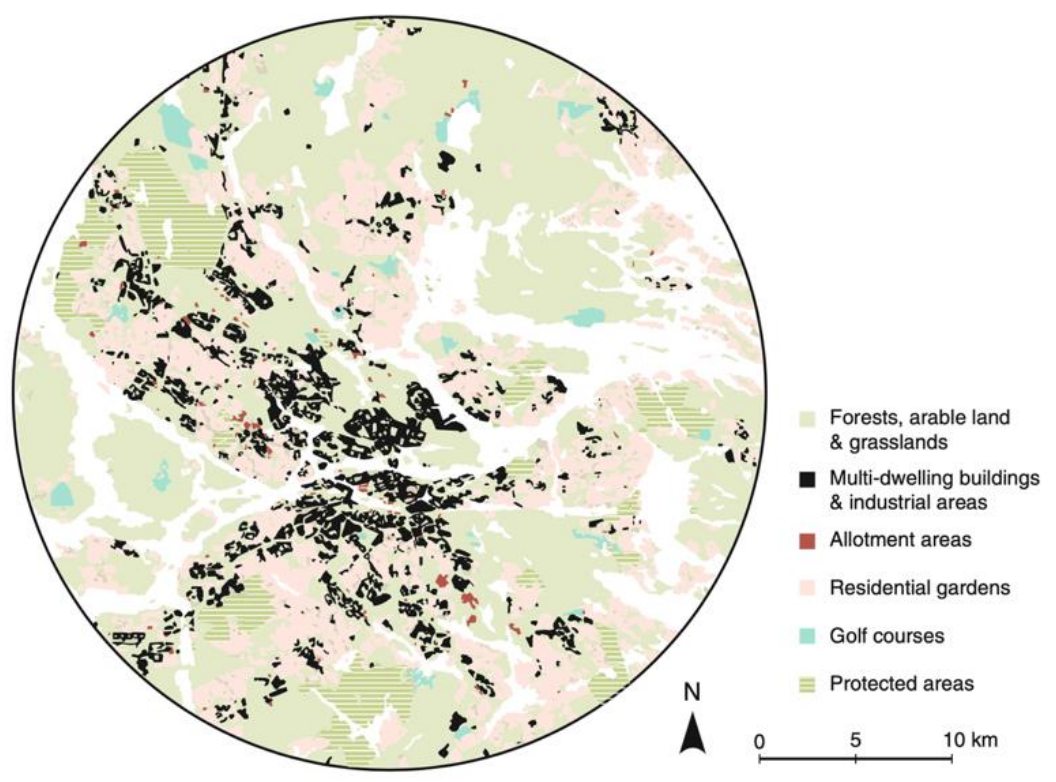

Nota: Revisitado por Johan Colding y el Stockholm Resilience Center en 2013. Fuente: Colding, 2013.

ACE, 16 (4.6) CC BY-ND 3.0 ES | UPC Barcelona, España | Invertir la mirada: los vacíos metropolitanos como elementos estructurantes del territorio de Estocolmo. DOI: http://dx.doi.org/10.5821/ace.16.46.9894 
El reconocimiento de la importancia de los espacios verdes y los sistemas ecológicos es creciente tanto en el terreno de la investigación académica como en el de las prácticas profesionales e institucionales, como lo demuestra su inclusión en el planeamiento municipal y sobre todo regional. La escala metropolitana ha dotado al sistema de espacios verdes de nuevos usos recreativos vinculados al creciente interés por un modelo de urbanismo saludable y ha propiciado también la emergencia de nuevas sensibilidades respecto del entorno natural y a su preservación, como ha puesto de manifiesto la aparición de la categoría de 'patrimonio verde' como complemento a nociones más asentadas en el planeamiento de patrimonio histórico arquitectónico (Braae y Bøggild, 2015).

El actual plan de desarrollo para la región de Estocolmo, aprobado en 2018 y con prospectiva hasta 2050 (RUFS 2050), establece como líneas esenciales y estratégicas de desarrollo aspectos medioambientales y de salud, así como la inclusión, la accesibilidad y la equidad. El plan afronta una hipótesis de crecimiento demográfico de un millón de habitantes, pasando así de los 2.5 a los cerca de 3.5 millones de habitantes en 2050, suplementando la construcción de nuevos asentamientos residenciales con criterios relativos a la eficiencia en el consumo y la gestión de recursos, a la escasez de las capacidades del territorio y al incremento de la accesibilidad a los servicios públicos. Como principios organizativos establece, entre otros, la cohesión de la estructura verde metropolitana y el refuerzo de las conexiones entre los ámbitos urbano y rural (Figura 10). Sin embargo, lo que no está todavía muy desarrollado, y que nos parece de una gran importancia estratégica, es el estudio comparado o integrado de los sistemas de vacío con otros sistemas urbanos, poniendo así en relación modos de producción, distribución y consumo metropolitanos con sus cristalizaciones morfológicas.

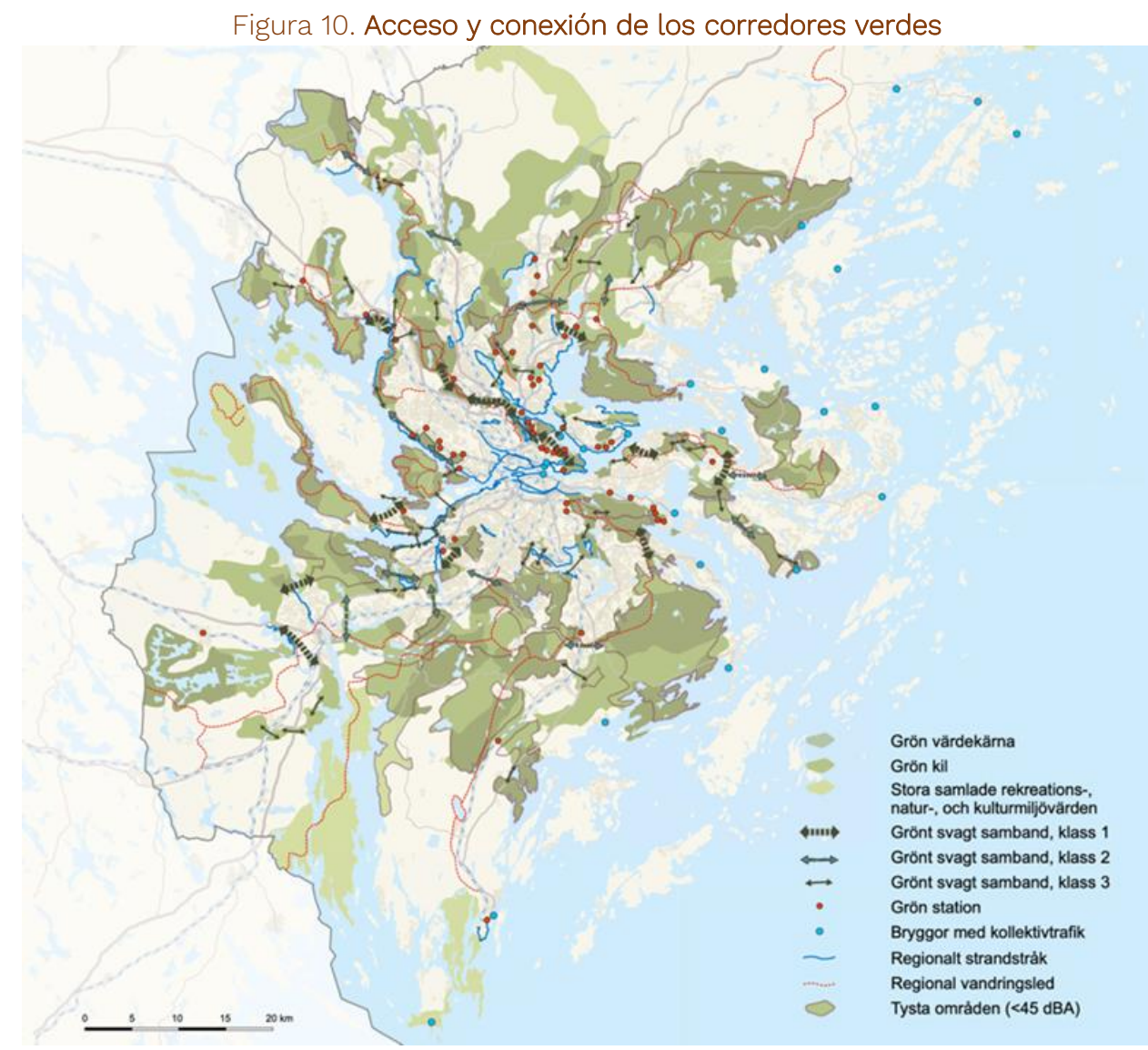

Nota: Clasificación de zonas verdes según valor y uso, junto a sistema de acceso y movilidad en zonas de agua, en el Plan de desarrollo regional de la región de Estocolmo. Fuente: RUFS, 2018.

ACE, 16 (4.6) CC BY-ND 3.0 ES | UPC Barcelona, España | Invertir la mirada: los vacíos metropolitanos como elementos estructurantes del territorio de Estocolmo. DOI: http://dx.doi.org/10.5821/ace.16.46.9894 


\section{Conclusión: El vacío urbanizado}

¿Cómo evaluar hoy, desde una perspectiva contemporánea, esta historia sobre desarrollo urbano de Estocolmo? ¿De qué manera se puede restructurar el legado fragmentado del mijlonprogram integrándolo en un sistema territorial más cohesivo? ¿Qué papel puede jugar el sistema de espacios vacíos que los distintos planes han ido progresivamente generando dentro del futuro planeamiento de Estocolmo?

Las nociones de urbanidad típicamente asociadas a centralidad, a un espacio geográficamente central, sociológicamente homogéneo, demográficamente denso, morfológicamente compacto y funcionalmente diverso (mezcla de usos residencial, oficina, servicios y equipamientos) es predominante en Suecia. En concordancia con esta concepción de centralidad y el marco de un amplio consenso político y profesional con muy pocas voces disonantes (Carbonell, 2021), se ha establecido la principal estrategia de renovación urbana para Estocolmo. Esta tendencia hacia una creciente "densificación" y "recentralización" ha dado lugar, en los últimos años, a tres grandes operaciones urbanísticas que ocupan espacios previamente destinados a usos productivos (industria, puerto y espacios logísticos): las distintas fases del área de Hammarby Sjöstad, la reconversión de las cinco zonas portuarias englobadas en el desarrollo Norra Djurgårdsstaden y el reciente proyecto de Hagastaden en el límite norte del municipio. De este modo se pretende consolidar la compacidad de la ciudad central ocupando los pocos espacios vacíos urbanos existentes. Un criterio, por otro lado, común a tantas ciudades europeas, que ignora la singularidad metropolitana en base a la cual la ciudad-región de Estocolmo se construyó durante la segunda mitad del siglo XX. Consecuentemente, el énfasis puesto en la ciudad central y compacta desestima la escala territorial como sustento de un proyecto metropolitano de equilibrio y redistribución. Por el contrario, en oposición a la estrategia de re-densificación de los centros urbanos, la metrópolis horizontal como sistema redistributivo permitiría reducir las relaciones jerárquicas dominantes basadas en un modelo de zonificación obsoleto y en un principio de concentración que conlleva polarización territorial y segregación (Figura 11).

En las dos últimas décadas, estudios sobre el paisaje urbanizado han propuesto un reconocimiento de los espacios no edificados como elementos que no solamente acompañan, sino que articulan la ciudad y el territorio (Secchi, 1986, 2011; Viganò, 1999). Por otro lado, los procesos de urbanización extensiva, el crecimiento explosivo de las grandes urbes, el encadenamiento de aglomeraciones metropolitanas, o las profundas alteraciones de entornos rurales, requieren una urgente actualización de la relación entre los espacios construidos y los no construidos (Brenner, 2009, 2019). En efecto, propuestas como la ciudad difusa ampliaron el foco de estudio a una escala regional ya en los años 90 (Indovina, 1990). En la misma línea, el estudio de territorios dispersos y sus morfologías (Boeri et al., 1993; Viganò, 2001, 2004), han cuestionado el mito de la ciudad compacta, así como la idea misma de lo urbano como circunscrita al espacio de la ciudad, como objeto delimitable. Más recientemente, los trabajos de Paola Viganò y Bernardo Secchi han dado un nuevo paso al considerar los territorios dispersos como formas de capital social, espacial y natural (Viganò, Secchi y Fabian 2016), dotándolos de un carácter proyectual, o cuanto menos evaluable en términos de planeamiento y diseño metropolitanos.

De este modo, la comprensión de los espacios no edificados como estructurantes de la metrópolis deviene esencial para re-conceptualizar la forma urbana contemporánea. Paola Viganò ha ensayado varios proyectos que piensan y proyectan la región metropolitana, como son la ciudad inversa (1999), la ciudad porosa (2009) o la metrópolis horizontal (Viganò et al., 2017, 2020). Nos interesan estas referencias en cuanto aproximan el estudio metodológico de las morfologías metropolitanas y regionales a la práctica urbanística. Son proyectos que apuestan por un modelo inclusivo y redistributivo de los servicios urbanos, en contraposición a los modelos de densificación y

ACE, 16 (4.6) CC BY-ND 3.0 ES | UPC Barcelona, España | Invertir la mirada: los vacíos metropolitanos como elementos estructurantes del territorio de Estocolmo. DOI: http://dx.doi.org/10.5821/ace.16.46.9894 
recentralización, que tienden a privilegiar situaciones de exclusividad y limitación en el acceso a dichos servicios, ya que suponen una concentración de lo urbano, tanto en lo formal como en lo económico. La estrategia de limitar, o incluso de revertir, el crecimiento urbano en respuesta a los procesos de urbanización extensiva de las últimas décadas, parecerían adecuados en un contexto como el actual, de grave crisis ambiental y climática, y con unas desigualdades económicas fuertemente arraigadas en patrones de urbanización desigual (Smith, 1984). Sin embargo, creemos que la concentración en espacios densificados tensaría aún más la polarización centro/periferia, urbano/no-urbano, a la vez que ahondaría en la estrategia de propulsar al extra-radio (o al territorio, a la región, al afuera del sistema urbano) aquellas funciones en litigio con la vida urbana, aquellas actividades consideradas no compatibles con el espacio urbano. Se trata, por otro lado, de una estrategia que ha sido utilizada de forma generalizada en los crecimientos urbanos del último siglo, los cuales han tendido a externalizar el desarrollo industrial (actividades productivas, logísticas e industriales, infraestructuras energéticas y de tratamiento y gestión de residuos, plantas de reciclaje, redes de transporte inter-regional, espacios de ocio grandes superficies de consumo, etc.).

Figura 11. Plan de desarrollo de la región de Estocolmo con proyección 2030

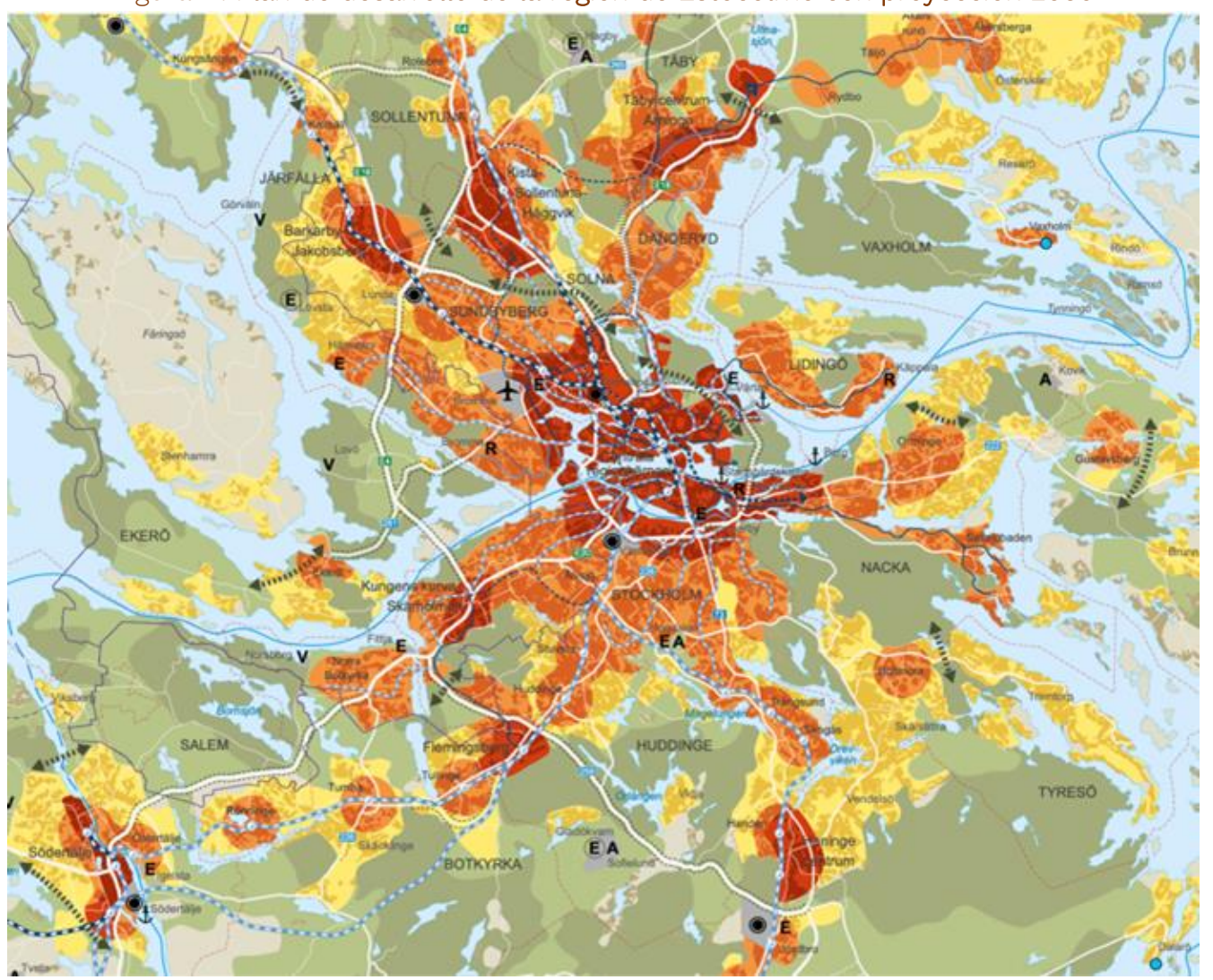

Nota: El mapa muestra la estructura del territorio metropolitano y sus vacíos, así como relaciones de densidad, posibilidades de desarrollo de los distintos municipios y conexiones débiles en sistemas ecológicos a considerar. Fuente: RUFS, 2018.

Por otra parte, los considerados vacíos urbanos, como hemos enunciado con anterioridad, obviamente no lo están. Es decir, no son espacios carentes de materialidad, función, explotación o marco regulatorio. En realidad, los llamados vacíos urbanos designan una ausencia muy particular: la de edificios. Los vacíos urbanos tienen, en realidad, una plenitud otra, su ocupación está expresada en planes y proyectos, así como regulada por normativas y marcos legales operando en distintos niveles administrativos. Los vacíos urbanos son, fundamentalmente, parte sustancial de la urbanidad

ACE, 16 (4.6) CC BY-ND 3.0 ES | UPC Barcelona, España | Invertir la mirada: los vacíos metropolitanos como elementos estructurantes del territorio de Estocolmo. DOI: http://dx.doi.org/10.5821/ace.16.46.9894 
contemporánea, de nuestra forma de pensar y percibir la condición urbana. Estos espacios no edificados son, en muchos casos, el resultado de largos procesos de explotación y gestión del suelo. Con las nuevas consideraciones recientes que están redefiniendo las relaciones ciudad-naturaleza, los sistemas ecológicos se han ido consolidando como parte constitutiva del espacio urbano, contribuyendo así a nuevas formas de bienestar y de preservación, no únicamente social sino también medio-ambiental. Así, la idea de metrópolis horizontal propuesta por viganò, abre la puerta al reconocimiento de la complejidad del territorio metropolitano, a la vez que permite pensar en una estrategia de desarrollo sostenible -o más bien reconfiguración- a escala territorial basada en criterios de redistribución, proximidad e igualdad, haciendo del mismo tejido metropolitano un sistema ecológico que sostenga un modelo metropolitano sostenible. Según la hipótesis de Viganò, una realidad "urbana heterogénea y policéntrica, estructurada alrededor de espacios abiertos y con la capacidad de integrar varias funciones, está ya en construcción”, y se definiría como en entrelazamiento de las esferas rurales y urbanas, formando un "sistema de comunicación, transporte y actividad económica descentralizado y multipolar, y a su vez cohesivo y dinámicamente organizado” (2017, 90). Como ya anticipó Bernardo Secchi en sus trabajos en Amberes, la condición contemporánea no somete a tanto estrés el tejido urbano como la modernidad industrial del siglo XIX, o incluso el despliegue territorial de la modernidad del XX, sino que muestra más atención a lo que él llama compatibilidad ambiental, a una porosidad metropolitana que expresaría la continuidad, intensidad y entrelazamiento de actividades y usos en la ciudad en su escala territorial. ${ }^{2}$

Esta tradición de estudios que relacionan redistribución, vacío y paisaje constituye un apoyo fundamental para reequilibrar y redistribuir la estructura urbana de Estocolmo. La importancia de la singular geografía física de Estocolmo convierte esta metrópolis en un caso de estudio particularmente relevante, aunque las consideraciones que extraemos como conclusión podrían ser válidas parar otros espacios metropolitanos. El estudio de la correlación entre sistemas de espacios no edificados y su impacto en la densidad, la demografía y la segregación social, serán necesarios para pensar un territorio metropolitano con criterios redistributivos en cuanto al acceso a los recursos urbanos. De igual forma, la cuestión metabólica en el paisaje de los territorios metropolitanos será cada vez más un aspecto fundamental si se quiere avanzar hacia un modelo de metrópolis sostenible para el futuro. Estos son retos que las administraciones, tanto municipales como regionales, parecen no estar considerando suficientemente, o cuanto menos no de forma integrada. Esto es, es conveniente añadir a las funciones derivadas del modelo de densificación según criterios de centralidad -vivienda, oficina, comercio y ocio-, los espacios y sistemas productivos, logísticos, la gestión del agua, los ciclos de reciclaje y tratamiento de residuos, los sistemas ecológicos y biotopos, así como la generación y distribución de energía. La introducción de estas capas al análisis de la morfología metropolitana y sus sistemas vertebradores proveerán una lectura más precisa de sus relaciones internas e interdependencias, facilitando el diseño de estrategias de transformación de los territorios metropolitanos en toda su complejidad. En el caso de Estocolmo, repensar el sistema de vacíos producido durante el proceso de metropolitanización permitiría, tanto favorecer la integración de los distintos suburbios, como acomodar los procesos metabólicos y productivos que la ciudad ha considerado como externalidades hasta el momento.

\section{Autoría}

El primer autor ha diseñado la investigación y el caso de estudio. La escritura del artículo se ha realizado conjuntamente por parte de los dos autores.

\footnotetext{
2 Secchi se refiere al término porosidad en la significación que le da Walter Benjamin en su escrito sobre Nápoles, es decir, la continuidad, intensidad y entrelazamiento de actividades y usos en la ciudad.
}

ACE, 16 (4.6) CC BY-ND 3.0 ES | UPC Barcelona, España | Invertir la mirada: los vacíos metropolitanos como elementos estructurantes del territorio de Estocolmo. DOI: http://dx.doi.org/10.5821/ace.16.46.9894 
Conflicto de intereses: Los autores declaran que no hay conflicto de intereses.

\section{Bibliografía}

Abercrombie, P. (1944). Greater London Plan. London, Reino Unido: His Majesty's Stationery Office.

Barles, S. y Lestel, L. (2007). The Nitrogen Question: Urbanization, Industrialization, and River Quality in Paris, 1830-1939. Journal of Urban History, 33(5), 794-812. DOI: https://doi.org/10.1177/0096144207301421

Bélanger, P. (2009). Landscape as Infrastructure. Landscape Journal, 28(1), 79-95. Recuperado de https://www.jstor.org/stable/43324425

Bengtzon, O., Lenden, J. y Lundgren, J. (1970). Rapport Tensta. Estocolmo, Suecia: Pan Express.

Berger, A. (2006). Drosscapes: Wasting Land in Urban America. Nueva York, Estados Unidos: Princeton Architectural Press.

Braae, E. (2015). Beauty Redeemed: Recycling Post-Industrial Landscapes. Risskov/Basel, Suiza: Ikaros Press/Birkhäuser Verlag.

Braae, E y Bøggild, S. S. (2015). The Green Heritage of the Danish Welfare State. Nordic Journal of Architecture, 5, 84-93.

Brenner, N. (2009). Restructuring, Rescaling and the Urban Question. Critical Planning, 16, 61-79.

Brenner, N. (2019). New Urban Spaces: Urban Theory and the Scale Question. Nueva York, EUA: Oxford University Press.

Bøggild, S. S. (Forthcoming). Too Bad to be True or Too Good to Be Credible - A Tale of Two Towns. En Crimson Historians and Urbanists (Eds.), New Towns on the Cold War Frontier (pp. 66-273). Rotterdam, Holanda: Crimson Architectural Historians.

Carbonell, A. (2016). Spatial Practices in an Urban World: Reassessing Territory and Ecology as a New Ground for Architecture and Urban Design. ZARCH Journal of Interdisciplinary Studies in Architecture and Urbanism, 7, 120-130. DOI: https://doi.org/10.26754/ojs zarch/zarch.201671520

Carbonell, A. (2021). Can Our Suburbs Survive? The Question of Density in Times of Pandemic. PLAN, 76 (1-2), 119-126.

Corner, J. (1997). Ecology and Landscape as Agents of Creativity. En G. Thomson y F. Stainer (Eds.), Ecological Design and Planning (pp. 80-108). Nueva York, EUA: John Wiley \& Sons.

Corner, J. (2006). Terra Fluxus. En C. Waldheim (Ed.), The Landscape Urbanism Reader (pp. 21-33). Nueva York, EUA: Princeton Architectural Press.

Forman, R.T.T. (1995). Some general principles of landscape ecology. Landscape Ecology, 10 (3), 133142. DOI: https://doi.org/10.1007/BF00133027 
Gandy, M. (2004). Rethinking urban metabolism: water, space and the modern city. City, 8(3), 363-379. DOI: https://doi.org/10.1080/1360481042000313509

Gandy, M. (2014). The Fabric of Space Water, Modernity, and the Urban Imagination. Cambridge, EUA: The MIT Press.

Heynen, H. (1999). Architecture and Modernity: A Critique. Cambridge, EUA: The MIT Press.

Indovina, F. (1990). La città diffusa. En F. Indovina et al. (Eds.) La città diffusa (pp. 19-43). Venecia, Italia: Daest.

Legeby, A. (2013). Patterns of co-presence: Spatial configuration and social segregation. Estocolmo, Suecia: KTH/ARK Akademisk avhandling.

Markelius, S. (1946). The Framtida Stockholm. Riktlinjer för Stockholms Generalplan. Estocolmo, Suecia: Stockholms Stads Stadsplanekontor.

Mattsson, H. y Wallenstein, S.-O. (2010). Swedish Modernism: Architecture, Consumption and the Welfare State. London: Black Dog Publishing.

Mostafavi, M. y Doherty, G. (2011). Ecological Urbanism. Cambridge, EUA y Berlin, Alemania: Harvard University Graduate School of Design y Lars Müller.

Höjer, J., Ljungqvist, S., Poom, J. y Thörnblom, I. (1997). Vällingby, Tensta, Kista, vadå? Arkitektur, 77 (2) , 16-21.

Reed, C. y Lister, N-M. (2014). Projective Ecologies. Nueva York, EUA: Harvard Graduate School of Design y ACTAR.

Rudberg, E. (2017). A tribute to the Memory of Sven Markelius and Uno Ahrén. Estocolmo, Suecia: Royal Swedish Academy of Engineering Sciences.

Salgueiro Barrio, R. (2016). Birds Must Be Eliminated: Air Architecture and the Planetary Reenactment of the Modern Void. Journal of Architectural Education, 70(2), 311-323. DOI:

https://doi.org/10.1080/10464883.2016.1197679

Secchi, B. (1986). Progetto di suolo. Casabella, 520/521, 19-23.

Secchi, B. (2011). La nuova questione urbana: Ambiente, mobilità e disuguaglianze sociali. Crios, 1, 8998.

de Solà-Morales, M. (2009). Los vacíos de la metrópolis. En L. G. Alfaya y P. Muñiz (Eds.), La ciudad, de nuevo global (pp. 129-139). Santiago de Compostela, España: Colexio Oficial de Arquitectos de Galicia.

Smith, N. (1984). Uneven Development: Nature, Capital and the Production of Space. Athens, EUA y Londres, Reino Unido: The University of Georgia Press.

Ståhle, A. (2008). Compact sprawl: Exploring public open space and contradictions in urban density. Estocolmo, Suecia: Akademisk avhandling.

ACE, 16 (4.6) CC BY-ND 3.0 ES | UPC Barcelona, España | Invertir la mirada: los vacíos metropolitanos como elementos estructurantes del territorio de Estocolmo. DOI: http://dx.doi.org/10.5821/ace.16.46.9894 
Ståhle, A. y Caballero, L. (2010). Greening metropolitan growth: integrating nature recreation, compactness and spaciousness in regional development planning. International Journal of Urban Sustainable Development, 2 (1-2), 64-84. DOI: https://doi.org/10.1080/19463138.2010.512496

Sidenbladh, G. (1969). Introduktion till dispositionsplan för Järvafältet. Arkitektur, 1, 6-7.

Sidenbladh, G. (1981). Planering för Stockholm 1923 - 1958. Estocolmo, Suecia: Liber Förlag.

Stockholms Stad Stadplanekontor (1952). Stadeplanekontorets förslag till generalplan för Stockholm stad 1952. Estocolmo, Suecia: Stockholms Stads Stadsplanekontor.

Viganò, P. (2009). The Metropolis of the Twenty-First Century. The Project of a Porous City, OASE Journal of Architecture, 80, 91-107.

Viganò, P. (2013) The Horizontal Metropolis and Gloeden's diagrams. Two parallel stories. OASE Journal of Architecture, 89, 94-103.

Viganò, P.; Secchi, B. y Fabian, L. (Eds.) (2016). Water and Asphalt: The Project of /sotropy. Zurich, Suiza: Park Books.

Viganò, P. y Cavalieri, C. (Eds.) (2019). The Horizontal Metropolis. A Radical Project. Zurich, Suiza: Park Books.

Viganò, P., Arnsperger, C., Barcelloni Corte, M., Cogato-Lanza, E. y Cavalieri, C. (2017). Rethinking Urban Form: Switzerland as a "Horizontal Metropolis". Urban Planning, 2(1), 88-99. DOI: https://doi.org/10.17645/up.v2i1.871

Waldheim, C. (Ed.) (2006). Landscape urbanism reader. Nueva York, EUA: Princeton Architectural Press.

Waldheim, C. (2016). Landscape as Urbanism: A General Theory. Princeton, EUA: Princeton University Press. 